\title{
Principle and Conducting Manners of Creating of Passive Defense Components as a Critical Artery
}

\author{
Moein Zargar ${ }^{1}$, Hossein Gholami ${ }^{2}$, Hossein Norouzi ${ }^{3}$, Morteza Soltani ${ }^{4}$, Shahide Dehghan ${ }^{5}$, \\ Majedeh Haeri-Hamedani ${ }^{6}$, Saeid Eslamian ${ }^{6}$, Vijay P. Singh ${ }^{7}$, Mohsen Ghane ${ }^{8}$, \\ Kaveh Ostad-Ali-Askari ${ }^{*}$ \\ ${ }^{I}$ Department of Civil Engineering, Farzanegan Institute of Higher Education, Isfahan, Iran \\ ${ }^{2 *}$ Department of Civil Engineering, Isfahan (Khorasgan) Branch, Islamic Azad University, Isfahan, Iran \\ ${ }^{3}$ Department of Civil Engineering, Maybod Branch, Islamic Azad University, Maybod, Yazd, Iran \\ ${ }^{4}$ Department of Architectural Engineering, Shahinshahr Branch, Islamic Azad University, Shahinshahr, Iran \\ ${ }^{5}$ Department of Geography, Najafabad Branch, Islamic Azad University, Najafabad, Iran \\ ${ }^{6}$ Department of Water Engineering, College of Agriculture, Isfahan University of Technology, Isfahan, Iran \\ ${ }^{7}$ Department of Biological and Agricultural Engineering \& Zachry Department of Civil Engineering, Texas A \\ and M University, 321 Scoates Hall, 2117 TAMU, College Station, Texas 77843-2117, U.S.A.
}

${ }^{8}$ Civil Engineering Department, South Tehran Branch, Islamic Azad University, Tehran, Iran

*Corresponding Author: Dr. Kaveh Ostad-Ali-Askari, Department of Civil Engineering, Isfahan (Khorasgan) Branch, Islamic Azad University, Isfahan, Iran

\begin{abstract}
In according to ratification of overview document and forth plan of law, the attention to the field of passive defense will create in conducting level for performing organizations. Although in recently circumstances nobody had no doubt about the necessity of implementation of passive defense for all critical, sensitive and important facilities and areas but till complete establishing of conductive system of research for further information and data for plan performing in all executioner organizations and passive defense culture distribution is on the command of engineer society. This article tried to explain design and conducting methods in the field of passive defense as a crucial artery of ministry of energy including camouflage, deceive, navigation, divorcement, diffuseness and steel structures.
\end{abstract}

Keywords: passive defense, artery, conductive system, energy, field.

\section{INTRODUCTION}

Passive defense refers to the actions in which to use them without using any kinds of warfare but preventing from attack possibility and reduce casualty and damage from enemy invasions.

Use of manner of passive defense based on passive doctrine, demands deep knowledge about advantage of recently high teach and all materials for approving them and modern methods for opposition against them. Main targets of passive defense will focus on supporting human force and national critical facilities. In this regard all programs will design under command of this field rather than attention to the security and economic issues should try to increase national capacity for opposition against threats and attack possibility.

And promote abilities and national patience for urgent situations.

In this case with increase enemy expenditure for invasion to the targets and delay in performing plans can reduce rate of attack to the country. Recently wars and last of them mean battle in southern province of Lebanon by Israel shows critical rules of energy including provides, transfer and division and nearby facilities for continue human life and defense forces.

This is one of the most special targets for enemy threats.

Identifying threats and warnings in cause of vastness of Iran with long border line in the sea and earth and variety of differentiation between province in the country, the level of the security for facilities 
and equipment could different from each other in ministry. Each of company should established in different level of security in the field of locating facility place and facilities technical elements to try to provide useful strategy in geographical under command areas.

Types of threats and warnings possibilities in facilities of ministry of energy

\section{OUTSIDE WARNING SYSTEM}

In all kinds of war and struggle, invader army in accordance with identifying targets, resistance defense power of another side of the war using different weapons. Attack to the targets should prepare from air and earth or sea. Electrical facility with important rule in daily life of people should select for initiative targets for attacking. Possible threats for industrial and electrical facilities categorized below

- Enemy direct attack with using known weapons such as air bombardment, missile attack, artillery and rockets.

- Sabotage activities in electrical and electronics transfer facilities.

- Enemy direct attack with unknown weapons such as chemical, virus, nuclear and neutron.

- Outage or lack of providing energy in cause of enemy attack into the ministry of energy systems (water and electricity) with graphite bombardment.

- Sabotage or infection planning by spy or secret agent.

- Creating disorders in pc systems and telecommunication channels by human factor or electromagnetic bomb effects.

- Destroying transfer, refining facilities by earthquake.

- Damage to the facilities by thunderbolt and lack of direct current and deeply damage by all mentioned causes above.

Damages caused by natural phenomena or human errors have no differentiation in the final results with none-natural phenomena and in all circumstances can change to cause of lack of electricity in the powerhouse can cause for lack of services but all fundamental frameworks will make for managing actions in hard situations should have power to control any problems from natural phenomena damages.

Those mentioned types of attack have relevant to war situation, enemy mode, national capacity of resistance, facilities distance from borderline and enemy targets.

In continue of subject we explain some usual methods of passive defense that which can usable for artery of ministry of energy.

\subsection{Hiding and Definition of Camouflage}

Include isochromatic and isomorph facilities with nature around them. Hiding can protect national forces from enemy observation and camouflage can reduce ability for identifying facilities place and actions and forces.

\section{Main Principles Of Camouflage}

\subsection{Camouflage and General Sign}

Camouflages have 2 parts. First with matching facilities with environment by painting with chemical and natural materials.

The second one is with transforming appearance can distract enemy from targets from identifying facilities and equipment in air photography and data gathering by intelligence squad on earth need learning about sign and elements of camouflage conducting principles only for inspiration to the enemy all fake data we want.

All sign on earth and air classified in below

- movement

- sound/voice

- measure (facility and repair) 
- situation (locating at the right place)

- settlement appearance (organize settlement with discipline)

- epithelium (desert-civic-rural or arctic)

- fire and steam (all kinds of smoke and untimely fire)

- reflection (radar waves return from targets)

- shadow (till sun spark)

According to these mentioned items for establishing camouflage for critical artery should ratified all place and facility and equipment should use in specific for these targets and that all completely different from each other.

Locating place

Definitions of place location define as locality selection with enough equipment for hiding staff and equipment and action. In all area such as flat ground and desert have many different natural topography or human products could identify. Main principles of selecting area

- Mission is the critical and important base. Some place could suitable for hiding but if there not ability for access to doing mission it's worthless.

- Dispersion is measures of facilities needing depend on areas dimension. So, areas will select for mission should have complete dispersion and if don't have it, this place is unusable.

- modern camouflage

In order to daily upgrade tracking and identifying systems should use modern and recently equipment against them.

Today with developing seen identifying areas systems cover with electromagnetic waves such as visual amplifiers, thermal imaging, intelligible and controllable rockets and satellites can arm with millimeter radars and heating tracking systems. This high teach of equipment using multitasking sensors. Prepare phantoms with these systems and rockets can create major warning for all military and strategic targets such as military vehicles, bomber sites, oil platforms and refinery. All of them will under major warning. Actions against this sensor can show national power of defense. All of enemy equipment could using against facilities of ministry of energy arm with this multitasking sensor. Now explain some way for opposition against them

\subsubsection{Radar Absorbent Material}

Use of radar absorbent material cover (RAM) on steel part of facilities which can create main reflection.

\subsubsection{Carbon Fiber}

Use of materials such as carbon fiber which are transparent in front of microwaves.

\subsubsection{Geometry Form}

Using unique geometry form can make disorder in wave's effects in cause of factor for create problem in order to integration of waves opposite with route of gathering waves for receiver system. For sample low angle edge can work as a sharp angle edge.

\subsubsection{Use Some Materials Work as a Mirror}

This material term of use in prevent from effects of reflection edge such as collection of thin string in clear stuff cover.

\subsubsection{Intelligable Absorbent Stuff}

Multi spectrum intelligible stuff include active and passive stuff for reduce radar time delay level and prevent from sending thermal energy, mechanic waves, chemical effects, acoustic and magnetic from resource.

\subsubsection{Reduce Thermal Activity}

Reduce thermal activity and hiding military warfare exhaust with in access ways is one of the most important ways of camouflage tactics. 


\subsection{Camouflage Principles and Manners}

Conducting this tactic in the right way is the last tactics should be mention. When tegmen is weak in the earth or impossible to create natural structure for hiding we can use artificial materials for homochromatic facilities and equipment with nature for deceiving enemy in identifying targets, forces talent, mission target and fire deviation from real target based on 3 way

\subsubsection{Hiding}

In this regard explain some usual way of hiding

- assimilation

- transform and texture of area

- earth and air vision

- color, light and reflection

- shadow and shining

- similarity with nature

- prevent from observation and identifying

\subsubsection{Admixture}

It means use camouflage materials mentioned above and beside of determinate stuff with this issue that which includes a part of area.

\subsubsection{Enticement}

Change stuff performance with usual actions and redesign them to another shape. One of the ways of deceive is imitation. It's very smart choice for deceive enemy from real targets with transforming into other shapes and establish fake facility and material.

\subsubsection{Camouflage Tour}

This plan of deceive establish for beguile enemy from targets in 2 way

- change enemy focus from real targets

- Controlling enemy attack to lead to the fake facilities.

- importance and condition of fake facilities

In according to the recently high value of using fake facility only for deceive enemy we should focus on place and structure for heavy bombardment attack on the fake facilities. These kinds of cheat should have 2 or 8 kilometers far from real facility.

\section{A) Facility Imitates Characteristic}

Imitate facility should build from real facilities which don't have fine camouflage regarding to this subject have high priority

- deceiving performance

- realistic of fake facilities

- real facilities fine camouflage

\section{B) Errors and Problems in Deceiving Actions}

These are effective factors can affect on tricking process with failure. It's important about these factors is they have general usage and each one of them should use for specific situation. Otherwise they are useless.

- Failure on real building simulation

- Lack of vehicle and lack of usual transportation (in order to the right place and time)

- Lack of air defense position (for realistic of fake facilities)

- Failure in simulation of different parts of facilities 


\subsection{Anti Anti-Trick}

These manners based on enemy feeding information and controlling with under command systems for sending fake data and files and block these channels. These high developing manners can use from models with controllable electromagnetic waves reflection.

A) In appear bonds with satellite high power of analysis of place facilities should have include all simple sign of real building and nice simulation

B) Infrared bonds with satellite analysis of building

C) All facilities should have all simple sign of realistic place and all equipment and facilities should have nice thermal reflection for protection.

D) Developed models are one the most important part of trick plan and should design in manner of use all identifying details from satellite and rebuilt structure photos with electromagnetic waves.

- Resemblance in infrared bond

- Resemblance in appear vision bond

- Resemblance in radar bond

- Concordant between parts

- Use of main part

- Attention to the thermal capacity

In according to the different capacity of materials and attractive and reflection of thermal can ratify satellite. So, all homochromatic and same stuff should create from high frequency of real materials.

A) All necessary evidence should plan carefully and establish step by step

- Staff quartering

- Vehicle quartering

- Vehicle quartering of transport of logistic stuff such as oil, nutrition and accessory parts,

- Doing security actions

- Establishing fortress

- Camouflage

\subsection{Smoke Mission}

For covering facilities and equipment from far distance to dispose of some enemy controlling tactics in invasion equipment like optic, protection cover for repair and rebuilt of thermal fake facilities and establish passive defense system for firm structure beside sensitive place of powerhouse and prevent from accounting damage into the facilities and forces in cause of bombardment all reason for doing smoke mission.

\section{DISPERSAL AND DIVISION}

\subsection{Dispersal Includes Developing and Extent Facilities and Equipment in the Area}

Division include separation of some parts of facilities and human agent and supporting them into the safe area for reduce mortality from air attack and impose on enemy to using close sources against low value targets can reduce enemy attack.

Main factors in doing dispersal and division

All factors about these important tactics are include

- Technical characteristic of facilities and equipment (dynamic or static)

- Texture and extension of area (forest, desert, mountaineer, rural, village or beach)

- Numbers of human factors in each shift (max and min necessary time for each shifts)

- Expenditure efficient (accounting expenditure about the way of valuable facilities and area) 


\subsection{Division of Facilities and Fortress}

In the field of protection from some facilities and fortress over the observation of structure principles should pay attention to the division manner. Division actions include huge showing of warfare and equipment in the massive area and should mentioned as important way for save and survive and reduce damage for all important targets. Division creates small collection for enemy sensor. so, in enemy attack rate of casualty and damage stay in low. Division relevant to extension of sites when improve advance can make a large division into itself for increase rate of resistance and effective mission.

Common consideration for facilities of ministry of energy

Conducting division and dispersal don't have mean for complete stop of all common actions for industrial unit. These actions should reduce rate of vulnerable and continue process of conducting mission and service in the time of crisis.

- All of actions and plans should create for powerhouse and facilities in the manner of division principles and other rules of passive defense under command of experts.

- All forces for transporting sensitive materials which don't have enough time for transport and no place for them have reverse result. All actions should schedule by priority and time limit in the right way.

- Until conducting division and dispersal actions should estimate both air and infantry attack from enemy side.

- Camouflage, hiding, reinforcement and deceive are principles should consider when division or dispersal going to conduct and perform.

- Transporting of some of equipment and facilities of ministry of energy should transport in high level of security and use camouflage manners and other way of protection.

- For some static industrial units which do not use any plan for protection in huge scale can use part by part plan and in further time solve all problems on the way of conducting these plans.

- In special circumstances conducting principles of dispersal can hide facilities from forces on the earth but do not protect from air photography.

- Ground to air fire units have clarify and limit ability in the position. Position of this defense after navigation (searching sites) in the plan of anti-air force power cover and under command of mission commander should ratified distance between each equipment have restricted of mix and min are relevant to the plan of action and nature details kind of war zone area, anti-air attack units, vision angle and action area for all units.

\section{- Fortress}

Fortress refers to all structure using for reduce rate of damage from bullets or other weapons and protection from main facilities and sensitive place and bombardment include

- Materials and figure of fortress

- Bulkhead

- Sandbag

- Concrete slab- bunch of sand

- Walls

In front of main facilities use heavy or discharge or landing equipment transportation with use firm rail and create dynamic walls.

- Fortification of concrete slab with steel sheet

Kinds of armored steel sheets mentioned as

A) Sheets with hard face

B) Firm colleague sheet 
C) Flexible sheet

- Immunity and reduce warnings in main fortress

Most of facilities of ministry of energy in the field and wide areas in war time possible to getting damage hardly so try to reduce rate of warning from possible errors should prevent from enemy attack.
A) Create bulkhead
B) Bulk drainage
C) Formed bulk
D) Dividers and concrete ceiling

- Resistance component for safety from rockets and bullets (explosion)

In general prospect low contradictions observance and material thick the facilities fundamental components for controlling damages. This contradiction on books from ministry of residence or passive defense department.

\section{CONCLUSION}

This article suggests a new methodological procedure to management and passive defence Directed vigour for planetary advocacy is now a practical option and is premiere in many procedures to other offered technologies, being able to protect the Earth against all known menaces. With environmental preservation showy as the number one worldwide trouble, man has no option but to decrease his energy waster. Space and security realms are forcefully related with each other. However, space is defenseless itself to the new space warnings. All research show in the most of case happened some unforecastable problems from prevent damages. This subject is really important for identifying and knowing about systematic and controlling situations should attention to the issue below

- Chaos and division on establishing of facilities

- Camouflage and using hiding and deceiving

- Perfect and scientific methods

For navigation and preventing from attack

- Components protection with increase materials resistance

- Protection from explosion waves and bullets

- Using firm materials and safe

- Antimissile protection in high security place

\section{REFERENCES}

[1] A. Firth M, E. Shewen Pand,C. Hodgins D.2007. Passive and active components of neonatal innate immune defenses. Volume 6, Issue 2.December 2005, pp. 143-158.

[2] Koch V, Westphal R.1995. New approach to a multistatic passive radar sensor for air/space defense. IEEE Aerospace and Electronic... > Volume: 10 Issue: 11.

[3] Ronald W. R, Donald L. T, 1969. An analysis of active and passive defenses in inducing resistance to persuasion. Journal of Personality and Social Psychology, 11(4), 301-308. http://dx.doi.org/10.1037/ h0027354.

[4] Gapiński D, Krzysztofik I, Koruba Z.2018. Multi-channel, passive, short-range anti- aircraft defence system. Mechanical Systems and Signal Processing, Volume 98, 1 January 2018, Pages 802-815.

[5] Jared C, Antoniazzi M, E. C. Jordão A, et.al.2009. Parotoid macroglands in toad (Rhinella jimi): Their structure and functioning in passive defence. Volume 54, issue 3, 1 September 2009, Pages 197-207.

[6] Shi L, Zhang H, Li Z, et al, 2018. Analysis of moisture buffering effect of straw-based board in civil defence shelters by field measurements and numerical simulations. Building and Environment, Volume 143, 1 October 2018, Pages 366-377.

[7] Wiliams C, J.Galyean W, B.Welter K.2018. Integrating quantitative defense-in-depth metrics into new reactor designs. Nuclear Engineering and Design, Volume 330, 15 April 2018, Pages 157-165. 
[8] Sultan T, Sapra M, Kundo S, et al, 2017. Experimental \& analytical study of passive thermal sensing system developed for cooling water injection into AHWR core catcher. Nuclear Engineering and Design, Volume 322, October 2017, Pages 81-91.

[9] Parrott J, Metcalfe Ch.2018. Nest-defense behaviors in fathead minnows after lifecycle exposure to the antidepressant venlafaxine. Environmental Pollution, Volume 234, March 2018, Pages 223-230.

[10] Vincenzo A.D, Molino A.J, et al, 2017. Reservoir rehabilitation: The new methodological approach of Economic Environmental Defence. International Journal of Sediment Research, Volume 32, Issue 2, June 2017, Pages 288-294.

Citation: Moein Zargar, et.al. "Principle and Conducting Manners of Creating of Passive Defense Components as a Critical Artery”, International Journal of Constructive Research in Civil Engineering, 5(1), pp. 8-15. DOI: http://dx. doi.org/10.20431/2454-8693.0501002

Copyright: () 2019 Authors, This is an open-access article distributed under the terms of the Creative Commons Attribution License, which permits unrestricted use, distribution, and reproduction in any medium, provided the original author and source are credited. 